\title{
ISSUES IN FORECASTING PROSPERITY OF PLANT INTRODUCTION IN UZBEKISTAN
}

\author{
Belolipov Igor Vladimirovich \\ Professor of Department of Environmental Safety in Agriculture and Botany, Doctor of Biological
} Sciences, Tashkent State Agrarian University, Tashkent, Uzbekistan

Arabova Nodira Ziyodovna

Docent of Department of Environmental Safety in Agriculture and Botany, Candidate of Biological Sciences, Tashkent State Agrarian University,Tashkent, Uzbekistan

Islamov Avaz Musaevich

Assistant of Department of Environmental Safety in Agriculture and Botany, Tashkent State Agrarian University,Tashkent, Uzbekistan

Abdurasulov Shuhrat Ergashevich

Assistant of Department of Environmental Safety in Agriculture and Botany, Tashkent State Agrarian University,Tashkent, Uzbekistan

Article DOI: https://doi.org/10.36713/epra4691

\begin{abstract}
The article deals to bring theoretical and practical aspect of successful result of introduction of wild plants into Uzbekistan flora and estimates their resistancy to competition towards aborigen weeds.
\end{abstract}

KEY WORDS: Ecological factors, edaphic conditions, forecast, successful results.

\section{INTRODUCTION}

With the rise of the researches on the introduction of plants and attraction of new, foreign plants and sorts into conditions of Uzbekistan, this idea attains value of current interest. According to Suleymanov, Tellaev, Khudoybergenov, in a compilation of international conference materials, forecasted amount of harvest of any high-quality harvesting sort of plants in practice is gathered two times less than forecasted. Authors of abovementioned article explain this phenomenon so that our farmers are demonstrated high effect of any sort or hybrid in farming agricultures in Europe, the USA,
China and other countries, for the conditions of which given technologies have been elaborated ${ }^{1}$.

Authors apparently are coming to the conclusion that "initially these technologies should be learned in the conditions of Uzbekistan, and then to recommend them to farmers for production"2.

\section{METHODOLOGY}

A lot of medicinal, decorative, agricultural plants of nutritional and technical importance are introduced in Uzbekistan. While finding solutions for the problems arising from the process of adapting

\footnotetext{
${ }^{1}$ Sulaymanov, et.al. p. 361

${ }^{2}$ Ibid.
} 


\title{
EPRA International Journal of Research and Development (IJRD)
}

\author{
Volume: 5 | Issue: 6 | June 2020 \\ - Peer Reviewed Journal
}

plants into new conditions and forecasting probability of the results to be positive, "Introduction of plants", "Methodical recommendations regarding the study of introductory plants in conditions of Tashkent" and methodical recommendations of the book "Introduction of herbal plants of natural flora in the Middle Asia" were largely used. In this process scientific experience and observations of various scholars were also taken as a source.

\section{RESULTS AND DISCUSSION}

Searches of reliable forecast methods of prosperity of plant introduction of natural flora into concrete floristic field had not exceeded the frames of analogies (climatic, floristic, ecologic and etc.) before works of Vavilov (1965). To the matter of forecasting the prosperity of plant introduction, Vavilov heeded particular attention to direct geographic experience, pointing out that 'in order to assertively define aptness of cultivation, type or sort, one needs merely an experience ${ }^{3}$. The statement of scholar Vavilov is particularly relevant nowadays, with the mass import of species, sorts and highyielding hybrids into conditions of the Republic of Uzbekistan in order to increase crop yields of agricultural cultivations in conditions of the republic. For these plants of cultural flora, which are possessing valuable and useful features including high productivity of land, high quality of output, a significant point while introducing them into new habitats is conservation, and probably increase of productivity with implementation of certain technologies for specific sorts and hybrids. Taking into account climatic, floristic, and ecological and phytocenotic analogies intrinsically complement the ecological-introductive analysis and serve to increase the authenticity of introductive forecast.

Information regarding the biological, ecological, phenological and physiological features of a plant in the process of introductive experiment is crucial for evaluation of practical significance of plants and elaboration of issues in preserving the plant genetic stock and predicting the progress of an introduction experiment itself.

While evaluating the progress of introduction of plants of natural flora of Uzbekistan, attention should mainly be paid to the consistency (at least three years of the experiment) of seed renewal of self-sowing, annual renewal in particular.

By differentiating ability of plants to renewal and survival of self-seedingsunder specific environmental conditions, it is considered as one of the main indicators of prosperity of introduction experiment.

\footnotetext{
${ }^{3}$ Vavilov, 1965, p. 548
}

Competitive ability to weeds and other aboriginal species under conditions of introduction and the degree of prosperity of introduction possess a high degree of correlation (Belolipov, 1989).

Ecological and historical method of plant introduction not all the time can produce a positive response to the question in respect to the opportunity of the culture of any species in a certain natural area, although it is acceptable to explain the plant's reaction to new habitat.

Vavilov (1965) heeded particular attention to direct geographical experience in a question of forecasting the progress of plant introduction.

The ecological confinement of plants and their associations to certain environmental conditions is sometimes very conservative, due to the long-term development in a specific, slowly changing environment.

Reservoir plants, wet salt marshes, sand, gypsum are apparent examples of ecological conservatism. If all species of the genus or even of the family are strictly confined to specific identical living conditions, it is not realistic to hope for the introduction of these plants into another ecological environment to achieve progress.

On the contrary, with the lability of the sign of ecological confinement, which is always indicated by the ecological characterization of closely related species, much greater confidence for prosperity of introduced plants can be expected.

A preliminary study of the ecological confinement of all representatives of the taxon and, in particular, of systematically close units allows to predict the progress of the introduction with a high degree of probability. However, in order to increase the accuracy of the forecast, an introduction experiment is needed.

As an ecological introduction one, integrated method is used to study plants of the main types of vegetation in Uzbekistan. It is an organic method included in the group of methods for the investigational study of flora and vegetation. It is being applied for the purposes of involving in the experiment species which are intrinsic to each type of vegetation; above all, edificators and dominants, as well as other species intrinsic to this type.

The complexity of the ecological introductory method consists in attracting and using related botanical disciplines: botanical geography, geo-botany, ecology, physiology, morphology, anatomy, etc. the current level study of plant introduction by means of ecological introductory method involves obtaining data about the features and behaviour of plant organism in new habitat.

Therefore, the separation and research on the plant by the sum of its features helps to reveal patterns of phylogenetic order. 


\title{
EPRA International Journal of Research and Development (IJRD)
}

\author{
Volume: 5 | Issue: 6 | June 2020 \\ - Peer Reviewed Journal
}

The ecological introduction method also involves the identification of the 'amount of features' of the species, which are the 'clot' of their history.

Many species and genera of the haze family, for example, are edificators and dominants of halophilic vegetation in Uzbekistan. Moreover, completely different taxa of this family are analogous in physiological characteristics and ecologically belong to the group of salt-accumulating halophytes (haloxylon, potash, etc.). Number of adaptations of these species due to phylogenetic, and which are not so noticeable in places of natural habitat, is often clearly identified in the introduction experiment in conditions abruptly different from natural ones by eliminating competition of other species or partially weakening it.

On attracting the introduction of edificators, phytocenoses of various types of vegetation into Uzbekistan, we are disposed to expect an adequate response of these plants to new living conditions. This is particularly important for identifying the opportunities of cultivating endemic and relict, rare and endangered plant species of the natural flora of Uzbekistan.

Relying on the reaction of introducers to artificially changed living conditions (sudden weakening of competition, uniformity of edaphic conditions, etc.), we determine the potential introduction of this or that type of plant of vegetation of Uzbekistan.

As a result of initial introduction tests into soil-climatic conditions of Tashkent city (Botanical Garden), 711 species of herbaceous plants from 12 types of floral cover of Uzbekistan, including 66 species of rare and endangered plants listed in the Red Book of the Republic of Uzbekistan.

As a result of the introduction tests of wildgrowing species of the natural flora of Uzbekistan in Tashkent, a competitiveness of the introduced species was adopted as separate criteria for assessing the progress of the introduction, which was altogether justified. The degree of progress of introducing main types of floral cover in Uzbekistan is directly dependent on the competitive ability of the introducer.

The possibility of growing a number of species for many years under the edaphic conditions of the land, without substituting (without creating) edaphic conditions analogous to natural ones was revealed along with establishment of the facultative nature of many species of the natural flora of Uzbekistan in respect to the edaphic factor.

Species that are ecologically highly specialised, obligatory stenotopic according to the edaphic factor, apparently possess low competitiveness when introduced into the conditions of a botanical land.
The highest degree of success of introduction and competitiveness in Tashkent is observed in species introduced from phytocenoses, which have a high density of vegetation and a high degree of competition.

The lowest degree of success of introduction was noticed in species introduced from phytocenoses with a low completeness of vegetation cover, where coenotic connections between plants are not clearly expressed or do not exist at all (halophytes, psammophytes, upland xerophytes).

With the help of ecological-introductory analysis of plants of many types of vegetation in Uzbekistan, excepting the highland, it was revealed that plants of all other belts are promising for attraction into the culture.

As for Tashkent and for similar conditions, the most perspective plants are in foothills and in the tau belts. They turned out to be the most resistant to the initial introduction under the conditions of Tashkent. The degree of variability of the sign of obligation or optionality of the species as regards the environmental conditions identified during the introduction tests can be used to predict the outcomes of the introduction experiment with wild species of flora of Uzbekistan.

The most perspective ones for the introduction were eurytopic species with wide ecological amplitude, found in several types of vegetation, labile, easily adaptable to different edaphotopes and possessing high degree of competitiveness.

Thus, the prospects of applying the method of ecological productive analysis of plants of the main types of vegetation in Uzbekistan as the theoretical basis for the introduction of new species of wild plants with the aim of their further rational use and protection of plant resources of the natural flora of Uzbekistan have been established. Our proposed method increases the effectiveness of the introduction of flora inventory and increases the accuracy of prediction of the outcome of introduction researches in the field.

\section{CONCLUSION}

The level of variability of the mandatory or optional nature of the species in respect to edaphic environmental factors, identified during the introduction experiments, can be applied to predict the progress of the results of the introduction experiment. Determination of the forecast of the progress of plant introduction is an important element in evaluating the outcomes of the introduction experiment. 


\section{REFERENCES}

1. Sulaymanov B., Tellaev R., Khudoyberganov N., (2019) Sbornik materialov mezhdunarodnoy nauchno-prakticheskoy konferencii, SealMag, Tashkent, 396.

2. Vavilov N.I. (1965) Izbranniye trudy, L.Nauka, 786.

3. Belolipov I.V., (1989) Introuksiya travyanistyh rasteniy prirodnoy flory Sredney Azii (Ekologointroduksionniy analiz). FAN. 152.

4. Krasnaya Kniga Respubliki Uzbekistan. (2006) T.2. Rasteniya i griby, Chinor ENK.

5. Belolipov I.V., Tukhtaev B.Yo., Qarshiboev H. Q., (2015). "Usimliklar introduksiyasi" fanidan ilmiy - tadqiqot ishlari utkazishga oid metodik kursatmalar, $2^{\text {nd }}$ edition, Gulistan, $32 b$.

6. Belolipov I.V., Qarshiboev H.Q., Islamov A.M. (2017) "Toshkent shahri sharoitida yovvoyi usimliklarni introduksion urganishga oid metodik kursatmalar", Gulistan, 11 b. 